\title{
Myelopathy during treatment for pulmonary tuberculosis
}

\author{
Alison C. ReID \\ M.B. B.S., M.R.C.P., F.R.A.C.P. \\ I. BONE \\ M.B., Ch.B., M.R.C.P. \\ University Department of Neurology, Institute of Neurological Sciences, \\ Southern General Hospital, Glasgow G51 4TF
}

\begin{abstract}
Summary
A patient who developed a myelopathy during a course of treatment for pulmonary tuberculosis is described. The underlying mechanisms and problems in diagnosis are discussed.

\section{Introduction}

The onset of paraplegia in a patient undergoing treatment for pulmonary tuberculosis presents a diagnostic problem. The authors describe a patient who developed a myelopathy after 5 months of effective anti-tuberculous treatment. Demyelination is thought to have been the underlying cause, in the absence of any evidence to suggest active tuberculous involvement of the cord.
\end{abstract}

\section{Case report}

A 41-year-old man was transferred to the neurology ward. Four weeks previously he had noticed bilateral groin pains followed by progressive weakness of the legs. Over the past 2 days he had also developed loss of bladder sensation and the desire to void. Five months before, the patient had been undergoing treatment for pulmonary tuberculosis and his sputum had just become negative to culture. His current regime of anti-tuberculous therapy with ethambutol $900 \mathrm{mg}$, rifampicin $600 \mathrm{mg}$, isoniazid $300 \mathrm{mg}$ and pyridoxine $10 \mathrm{mg}$ all daily.

The patient was a thin man and general examination was normal. Neurological examination of the cranial nerves and upper limbs was also normal. There was complete paresis of the legs with brisk reflexes, ankle clonus and extensor plantar responses. Dense sensory loss was present below T12 with loss of vibration to the costal margin.

$\mathrm{Hb}$ was $11.9 \mathrm{~g} / \mathrm{dl}$ with the red cells being normochromic and normocytic. The white cells and platelets were normal. ESR was $120 \mathrm{~mm}$ in the first hour (Westergren). Serum urea and electrolytes, liver enzymes and blood sugar level were all normal. Protein electrophoresis revealed slight elevation in the $\alpha_{2}$ - and $\gamma$-globulins. Bence Jones proteins were not detected in the urine. Luetic serology was negative and serum vitamin $B_{12}$ and folate were normal.
There was no excess of urinary or blood porphyrins. Visual evoked responses were normal but no spinal evoked response could be elicited from stimulation of the common peroneal nerves. Chest radiograph showed extensive cloudy infiltration with some fibrosis and pleural thickening. Plain radiographs of the thoracic spine were normal and myelography was also normal. CSF microscopy revealed no cells or organisms; total protein was $0.6 \mathrm{~g} / 1$, albumin $0.22 \mathrm{~g} / \mathrm{l}, \mathrm{IgG} 0.03 \mathrm{~g} / \mathrm{l}$ and glucose $2.9 \mathrm{mmol} / \mathrm{l}$.

The patient was commenced on a decreasing course of corticosteroids over 3 weeks, while his usual anti-tuberculous regime was continued. After about 4 weeks, onset of clinical improvement occurred with gradually increasing power in the legs and a reduction in the sensory level. The ESR had fallen to $56 \mathrm{~mm}$ in the first hour.

\section{Discussion}

Tuberculous involvement of the spine, leptomeninges or cord had to be primarily excluded in this patient as a cause for the paraplegia. With normal plain radiography and myelography, and normal cerebrospinal fluid, however, there was no evidence for any active infective process. It is probably significant that the paraplegia occurred, not in the early stages of the active pulmonary disease, but after 5 months of anti-tuberculous treatment when the sputum had become negative to culture.

The possibility that the anti-tuberculous medications were responsible for the myelopathy also had to be considered, especially in view of the extensive literature describing their complications. Ethambutol is known to cause retrobulbar neuritis by a doserelated mechanism (Donomae and Yamamoto, 1966) and can also cause a peripheral neuropathy (Tugwell and James, 1972). Isoniazid may produce a peripheral neuropathy if pyridoxine supplements are not given (Dixon, Roberts and Tyrell, 1956), and optic neuropathy has also been described (Keeping and Searle, 1955). There certainly is no convincing evidence in the literature to incriminate these agents in the pathogenesis of a myelopathy. 
The anti-tuberculous regime was continued and the patient's clinical improvement took place while still taking medications-further evidence that they were unlikely to be of any aetiological significance.

Fortuitous multiple sclerosis was a possible diagnosis, but the patient had no past symptoms suggesting demyelinating disease or evidence of disseminated lesions. Both the optic discs and visual evoked responses were normal.

In 1977 Hughes and Mair reported 3 cases of acute necrotic myelopathy occurring in patients with active tuberculosis. All 3 patients came to postmortem and no evidence of tuberculous involvement of the cord, leptomeninges or spine was found. An immunological mechanism for the cord demyelination was postulated. They raised the possibility that hypersensitivity to a myelin auto-antigen plays a role in production of demyelination. The underlying mechanism of the myelopathy in the present patient is most probably similar to the cases reported by Hughes and Mair. Whereas their patients succumbed with massive necrotizing myelopathy, however, this patient displayed clinical improvement.
It is perhaps surprising that more cases such as this are not seen, as tuberculous infection may be $\frac{\pi}{2}$ likened to an infusion with Freund's adjuvant.

Demyelinating myelopathy certainly appears to $c$ be a rare, but distinct entity during the course of $\overrightarrow{\vec{B}}$ tuberculous infection. In the absence of a specific, $\vec{\square}$ reliable diagnostic test, this must remain a diagnosis $\frac{\square}{\circ}$ of exclusion, as active infective involvement of the $\overline{\bar{m}}$ cord must always be of foremost consideration.

\section{References}

Dixon, G.J., Roberts, G.B.S. \& TYRell, W.F. (1956) $\overrightarrow{\vec{\omega}}$ The relationship of neuropathy to the treatment of $\mathscr{\omega}$ tuberculosis with isoniazid. Scottish Medical Journal, 1, 흐 350.

Donomae, I. \& Yamamoto, K. (1966) Clinical evaluation of ethambutol in pulmonary tuberculosis. Annals of the New iু York Academy of Sciences, 135, 849.

Hughes, R.A.C. \& MAIR, W.G.P. (1977) Acute necrotic of myelopathy with pulmonary tuberculosis. Brain, 100, 223. i KeEPING, J.A. \& SeARle, C.W.A. (1955) Optic neuritis follow- G ing isoniazid therapy. Lancet, i, 278.

Tugwell, P. \& JAMES, S.L. (1972) Peripheral neuropathy 윽 with ethambutol. Postgraduate Medical Journal, 48, 667. 